\title{
Supporting integrated STEM in the elementary classroom: a professional development approach centered on an engineering design challenge
}

\author{
Anne T. Estapa ${ }^{1 *}$ and Kristina M. Tank ${ }^{2}$
}

\begin{abstract}
Background: Science, technology, engineering, and mathematics (STEM) education is becoming more prevalent at the elementary level, and there has been a push to focus on the integration between the STEM disciplines. Researchers within this study sought to understand the extent to which triads composed of a classroom teacher, student teacher, and an engineering fellow were able to use the context of an engineering design challenge to integrate and incorporate STEM concepts into the elementary classroom. Using a content analysis approach, researchers analyzed STEM integration across four phases of learning: professional development workshop, lesson plan, classroom enactment, and post-lesson reflection.
\end{abstract}

Results: Results highlight the ability for triads to conceptualize the integration of STEM concepts but also the challenge to sustain the integration of STEM concepts across phases of enactment.

Conclusions: The need to support teacher learning of STEM content and pedagogical practices for integration are discussed.

Keywords: Professional development, Engineering design, Elementary, STEM integration

\section{Background}

Science, technology, engineering, and mathematics (STEM) education is becoming more prevalent at the elementary level, and recent national reports have called for a change in how these disciplines are taught with an emphasis on the integration between the STEM disciplines (National Academy of Engineering and National Research Council 2009; 2011; 2012; 2014). Research, even in its infancy, indicates that the inclusion of engineering experiences within the STEM curriculum can develop young students' understanding of the various roles of engineering within the society as well as helping to enhance achievement, motivation, and problem solving by contextualizing mathematics and science content (Brophy et al. 2008; English and King 2015; Stohlmann et al. 2012). Elementary classrooms, therefore, provide a

\footnotetext{
* Correspondence: aestapa@iastate.edu

${ }^{1}$ lowa State University, 1660E Lagomarcino Hall, Ames, IA 50011, USA

Full list of author information is available at the end of the article
}

powerful environment for STEM implementation and learning. However, how teachers conceptualize, interpret, and subsequently enact STEM content and engineering impacts the learning experiences they provide in their classrooms (Diefes-Dux 2014). Therefore, it becomes imperative that we investigate how to better support teachers as they conceptualize integrated STEM and incorporate engineering-based STEM experiences into their elementary classrooms.

One of the ways that we can provide support for the inclusion of integrated STEM in elementary classrooms is through systematic and high-quality professional development (Guzey et al. 2014; Brophy et al. 2008; Roehrig et al. 2012). Professional development (PD) experiences can facilitate learning opportunities for teachers to acquire knowledge about new teaching practices or content (Estapa et al. 2016). Teacher PD programs typically seek to increase teachers' professional knowledge, challenge beliefs, improve classroom practices, and foster student 
learning and achievement gains (Borko et al. 2008; Guskey 1986; 2002). Research indicates that PD must be active, sustained, coherent, collaborative, reflective, and focus on content knowledge in order to lead to real changes in practice (Garet et al. 2001; Gamoran et al. 2006). Within STEM PD, research has found that there is a need to help teachers develop deeper understandings of disciplinary knowledge within the four disciplines (Brophy et al. 2008; Cunningham and Hester 2007; Ejiwale 2013), explore various mechanisms for integrating content across the disciplines (Moore, Stolhmann et al. 2014; Moore et al. 2014; Wang et al. 2011), and develop beliefs and understandings related to integrated STEM education (Roehrig et al. 2012; Stohlmann et al. 2012). Despite the existence of several PD opportunities focused on integrating STEM at the elementary level, there is limited research examining specific content and skills that are preferred when teaching integrated STEM and how these content and skills can be imparted to help with the widespread adoption of integrated STEM in elementary classrooms (O’Brien et al. 2014).

Therefore, within our study we sought to understand how triads' composed of a classroom teacher, student teacher, and an engineering fellow experience with a PD focused on STEM concepts and centered on the use of engineering design, impacted how they integrated and enacted these concepts in the classroom. The following research question guided our investigation: How do triads integrate STEM or STEM concepts into the classroom after participation in a PD focused on engineering design and structured to use engineering as a context for integration?

\section{Conceptual framework}

The conceptual framework that informed the design and provided guidance for the conceptualization of integrated STEM that was employed in this study was a blended model of two different STEM frameworks. The first of the two frameworks was the framework for STEM professional development (Roehrig et al. 2012), which defines STEM integration as the "merging of the disciplines of science, technology, engineering, and mathematics in order to help teachers to: (1) deepen student understanding of STEM disciplines by contextualizing concepts, (2) broaden student understanding of STEM disciplines through exposure to socially and culturally relevant STEM contexts, and (3) increase student interest in STEM disciplines to expand pathways for helping STEM fields" (p.35). The second framework was the framework for STEM integration in the classroom (Moore, Stohlmann et al. 2014; Moore et al. 2014), which suggests that high-quality STEM integration learning experiences should include the following: rich and engaging contexts that allow students to enter into the problem through multiple entry points, engineering design experiences where students can learn from failure, and standards-based mathematics and science content through student-centered pedagogies that promote teamwork and communication skills. While the two frameworks formed the foundation for this research, we further grounded our work in the literature focused on STEM integration within the elementary classroom and that ultimately informed the PD model that was used as teachers worked to align their practice with the Next Generation Science Standards (NGSS; NGSS Lead States 2013).

\section{STEM and engineering in the elementary classroom}

When looking at the literature on STEM integration, there is not a single definition or conceptualization of what STEM integration is or should look like at the elementary level (Breiner et al. 2012; Roehrig et al. 2012; National Research Council 2014). Johnson (2013) defines STEM as "an instructional approach, which integrates the teaching of science and mathematics disciplines through the infusion of the practices of scientific inquiry, technological and engineering design, mathematical analysis, and 21st century interdisciplinary themes and skills" (pg. 367). The 2014 report from the National Research Council titled, STEM Integration in K-12 Education: Status, Prospects, and an Agenda for Research, presents a more holistic definition of integrated STEM:

Rather than a single, well-defined experience, it involves a range of experiences with some degree of connection. The experiences may occur in one or several class periods, or throughout a curriculum; they may be reflected in the organization of a single course or an entire school, or they may be presented in an after or out-of-school activity (p.39).

Bybee (2013) also offers an intentionally broad and wide-ranging definition of STEM with the inclusion of nine commonly accepted models of integrated STEM and a description of how these models are different in the extent to which they integrate and include the four disciplines as they are largely context dependent. Breiner et al. (2012) present a similar argument that the construct of STEM has been defined as a range of ideas, and that these differing conceptualizations are largely based on the context or stakeholder who is promoting STEM. While the larger and more encompassing definitions of STEM allow for more flexibility with the contextual aspects of STEM, this also has raised concerns regarding the extent to which the four disciplines are or should be equitably represented within the larger construct of STEM (English 2015). Therefore, when thinking about the range in conceptualizations around STEM, 
there continues to be a need for a common perspective and vocabulary upon which researchers and educators can work towards a united goal (Berland 2014; National Research Council 2014; Roehrig et al. 2012). For this study, the definition of STEM presented by Moore et al. 2015 as "the teaching and learning of the content and practices of disciplinary knowledge which include science and/or mathematics through the integration of the practices of engineering and engineering design of relevant technologies" was adopted as it aligns with the conceptual framework of STEM utilized in this study.

\section{STEM integration and engineering design}

Despite the increasing interest in providing learning experiences that help students make connections across the STEM disciplines, there is limited research on which of the different STEM integration approaches best facilitate these connections and what factors make integration more likely to increase student learning, interest, or achievement in STEM (English and King, 2015; National Research Council, 2014). Additionally, while integration is not a new idea, STEM content has historically been taught in a siloed-manner that can make the recommended approaches of integrating across specific disciplines more challenging (Bybee 2010; National Academy of Engineering and National Research Council 2009; National Research Council 2014,). While integration can occur at different levels and among one or more of the STEM disciplines, one common approach to integrated STEM is through the use of engineering design as a context for learning within science and mathematics (Brophy et al. 2008; Moore et al. 2014; Bethke Wendell and Rogers 2013). Engineering is interdisciplinary in nature and requires the use of mathematical and scientific knowledge in order to solve the types of real-world problems that engineers generally face (Lachapelle and Cunningham 2014; Sheppard et al. 2009). The Framework for K-12 Science Education (National Research Council 2012), which forms the basis for the Next Generation Science Standards has also endorsed this idea of making connections between disciplines to help students gain an understanding that "science and engineering are instrumental in addressing major challenges that confront society today" (National Research Council 2012, p. 9). When looking at the inclusion of engineering design in K-12 classrooms, the Framework for K-12 Science Education (National Research Council 2012) states that "from a teaching and learning point of view, it is the iterative cycle of design that offers the greatest potential for applying science knowledge in the classroom and engaging in engineering practices" (National Research Council 2012, pp. 201-2). Therefore, highlighting the use of engineering design experiences within STEM provides an opportunity and context through which learning can be connected across disciplines (Moore et al. 2014).

In addition to providing ways for students to link and apply science and mathematics knowledge, engineering design provides an opportunity for students to engage with real-world contexts and problems that are authentic to engineering and help to illustrate the connections between learning and the real world (Bers et al. 2002; Brophy et al. 2008; Cunningham and Lachapelle 2014; Moore et al. 2014; Stohlmann et al. 2012). Engineering design experiences have been found to be intrinsically motivating for students as these experiences engage the students' natural desire and curiosity to solve problems and understand how things work (Adams et al. 2011; Carlson and Sullivan 2004; National Research Council 2014). Engineering design also provides an opportunity to develop problem-solving and self-guided inquiry skills as they work through the types of complex problems that are common to engineering (Crismond 2001; Cunningham and Hester 2007; Mehalik et al. 2008; Purzer et al. 2015). Finally, engineering design-based experiences can be used not only to facilitate interdisciplinary connections, but these types of experiences have been found to deepen conceptual understanding in other disciplines, like science (Kolodner et al. 2003; Mehalik et al. 2008; Bethke Wendell and Rogers 2013). For these reasons, several curricula have chosen to leverage engineering design experiences as an organizing framework for structuring learning experiences within STEM (Brophy et al. 2008; Cunningham and Lachapelle 2014; Kolodner et al. 2003; National Academy of Engineering and National Research Council 2009; Bethke Wendell and Rogers 2013).

With the recent recommendation for including a more integrated approach to STEM teaching and learning in the classroom (NGSS Lead States 2013; National Research Council 2012; 2014), the use of engineering design as a context for integrated STEM learning is a promising model that has the potential to provide several benefits related to teaching and learning within STEM. However, the inclusion of an engineering design-based approach to STEM integration at the elementary level also presents a number of challenges that need to be addressed in order to see effective and well-integrated STEM learning experiences. Elementary teachers often have limited content knowledge within engineering and STEM, limited access and exposure to quality curricular materials, experience time constraints for science and engineering instruction, and lack the materials and resources needed for effective implementation of integrated STEM instruction (Brophy et al. 2008; Moore et al. 2014). Additionally, elementary teachers have reported that they feel underprepared and overwhelmed in terms of the knowledge and beliefs related to engineering (Cunningham 2008; Lachapelle and Cunningham 2014; Diefes-Dux 2014). 
Therefore, to help teachers overcome some of these challenges and feel better prepared to integrate engineering and STEM in their classrooms, it is imperative that they are provided with PD that is grounded in the literature around what does and does not work (Moore et al. 2014; Brophy et al. 2008; Roehrig et al. 2012). This presents a challenge as there is a limited amount of research focusing on engineering-based PD and the specific content and skills that support the integration of engineering and STEM in elementary classrooms (O'Brien et al. 2014). Therefore, a purpose of this study was to add to the literature around how to better support teachers with the integration of engineering experiences within their STEM instruction. We aimed to develop a better understanding of how teachers' experiences within a PD affected the extent to which teachers were able to use the context of engineering design to integrate STEM concepts into their classroom.

\section{Methods}

We incorporated a qualitative content analysis (Schreier 2012) which allowed for the examination of STEM concepts and skills that teachers integrated following participation in a PD experience. A content analysis was chosen as this research method utilizes a systematic approach to make valid and replicable inferences from texts (Krippendorff 2013). More specifically, a summative approach (Hsieh and Shannon 2005) was utilized to explore usage of STEM concepts with a purpose to understand the interpretation of content across phases of learning. This approach allowed researchers to construct meaning through the analysis and interpretation of qualitative texts and materials (Schreier 2012). Due to the fact that content analysis involves the interpretation of texts by the researchers, Krippendorff (2013) suggests that to help ensure the validity and replicability of this analysis that the background and experiences of individual coders should be identified. The research team that participated in the content analysis consisted of two professors of STEM education, with an emphasis in elementary mathematics and elementary science and engineering. Additionally, each of the researchers had elementary teaching experience and had been involved in the planning and delivery of the professional development. We provide further context of the study and overview of methods in the following sections.

\section{Context of the study}

The participants of this study were part of a larger project focused on creating and testing a new model of teacher education designed to enhance elementary teachers' preparedness to teach STEM subjects. More specifically, efforts focused on the infusion of engineering design concepts into various components of an elementary teacher preparation program from content to methods courses and culminating in the student teaching experience. An essential feature of the program was a triad partnership between preservice teachers, cooperating teachers, and engineering graduate students that was designed to have each member bring a different set of expertise to the classroom. The triads work together during the 16-week student teaching placement to introduce upper elementary students to engineering concepts by integrating engineering activities in the cooperating teacher's classroom.

\section{Participants}

The participants $(n=30)$ were all part of the larger study and therefore each participant was part of a triad. The classroom teachers $(n=10)$ all taught in a large, urban district in the Midwest. The teachers are all self-selected into the larger study, showing an interest or commitment to bring engineering into the classroom. The student teachers $(n=10)$ were teacher candidates from one of two university licensure programs in the Midwest. All student teachers had completed the coursework needed for a degree completion specific to elementary education, but had not yet satisfied the student teaching aspect of their program. Student teachers were placed in a 16-week student teaching placement in one of the 10 classroom teacher's rooms. Student teachers also selfnominated into the larger study and were then selected based on criteria for professionalism. The engineering fellows $(n=10)$ were all graduate (master and doctoral seeking) students enrolled in an engineering program at a large, Midwest university. Graduate students applied and interviewed for work on the larger study. Once selected, engineering graduate students (fellows) were matched with a classroom teacher and student teacher to create a triad. The engineering fellow worked in the classroom 1 day a week to support the planning and instruction of science and math while working to also incorporate engineering.

\section{Professional development}

As part of their involvement in the larger project, participants participated in a week-long summer workshop prior to the start of the school year. The professional development (PD) was intended to provide support for the inclusion of STEM by providing participants with opportunities to engage with engineering content and practices as well as the use of engineering design-based learning of science and mathematics. In recognizing that each member of the triad partnership brought a different set of background knowledge, skills, and needs, the PD provided an opportunity to address the varying group needs as well as build a common understanding amongst participants. The first 3 days of the week-long 
workshop were only attended by the 10 engineering fellows and provided an introduction to professionalism and working in schools and to state and national science and mathematics standards and a focus on effective STEM teaching at the elementary level. As part of the discussion around effective elementary STEM teaching, the fellows participated in and discussed a lesson representing the learning cycle, viewed science and engineering lessons on video, and explored various models for integrating engineering into elementary science. For the final 2 days of the workshop, the majority of this time was spent in a whole group setting with the cooperating teachers and student teachers learning alongside the fellows in their triad teams. The first of the 2 days engaged participants in experiences around integrating science and engineering lessons, engineering design, and the use of engineering design as a context for integrating STEM in their classrooms. Efforts focused on providing experiences and knowledge for how to integrate STEM concepts within and across disciplines and examples for desired approaches and nondesired approaches were presented and discussed. While the second day also included engaging participants in experiences around engineering and integrated STEM, the larger focus of this final day was on designing engaging and integrated STEM lessons and co-planning STEM instruction for the upcoming semester.

Facilitators of the PD included three teacher educators within the STEM fields and three engineering professors of agricultural and biosystems, chemical and biological, and mechanical engineering. For the purposes of this study, the data collection specific to the summer workshop was focused solely on the last day during which participants experienced an engineering design challenge that they were then asked to implement in their classroom. We provide detail of the engineering design challenge in the section below.

\section{The engineering design challenge}

The engineering design challenge occurred on the final day of the workshop after participants had been exposed to engineering and engineering design-based STEM experiences on the previous day. The goal of this task was for participants to have an opportunity to extend and apply the knowledge obtained from previous PD tasks and discussions. Specifically, participants would engage with an engineering design challenge, work collaboratively to enhance the challenge to be more representative of engineering-design-based STEM instruction by tailoring it to grade level science and mathematics content, and then enact their version of the design challenge in the classroom. In recognizing that the triads are composed of multiple grade levels with different standards, the Hexbug design challenge was chosen due to the fact that there is a range of math and science concepts that can be integrated into this engineering design challenge.

Working with their triads, participants were introduced to the engineering design component of the lesson which was based in the use of an engineering design challenge that included criteria and constraints, building, testing, and sharing their designs. The specific engineering design challenge asked them to design a maze for a Hexbug by satisfying the following criteria: (1) the maze was at least 12 inch long, (2) the Hexbug had to travel from start to finish without escaping or being touched, (3) the Hexbug had to make at least two turns, and (4) the Hexbug had to climb over something or make a sound. The Hexbug is a battery operated, micro robotic creature that uses the physics of vibration to propel forward and explore its environment (https:// www.hexbug.com/).

Prior to building their mazes, participants were shown a list of the materials they could use to build their maze (i.e., aluminum foil, craft sticks, and construction paper) and introduced to the problem constraints such as, limited to five materials, 12 inches of tape, and $10 \mathrm{~min}$ of building time. To gain a better understanding of the material properties, groups were given a Hexbug and sample bag of all materials to explore and asked to generate a plan for their maze design. Once groups completed the building of their mazes, they did a gallery walk and tested each maze against the provided criteria and constraints to determine who satisfied the challenge.

The PD facilitators of this activity made purposeful decisions around its delivery. We worked to introduce and engage participants in the activity, while leaving room for activity improvement. For example, all participants completed the engineering design challenge but with little connection to STEM concepts or concept development. As Capobianco and Rupp (2014) express, for the integration of engineering to be fully realized, attention must be given to how teachers purposefully plan for and implement design-based instruction. Therefore, our PD design allowed us to identify the STEM concepts that triads included when asked to plan and enact an engineering design lesson in their elementary classroom.

\section{Data collection}

There were four data sources collected, as part of this study, that were used to capture the STEM concepts and skills that participants integrated following the PD. First, during the last day of the summer workshop participants experienced an engineering design challenge, as described above. After this experience, participants individually completed a survey (Additional file 1), which asked them to reflect on the content and pedagogy of the challenge. Second, each triad created a lesson plan for how they intended to incorporate the engineering 
design into their elementary classroom. Third, data was collected as the triads enacted the design lesson. Data from the enacted engineering design lessons included field notes from one or two observers (that were part of the larger research project team) and completion of a modified STEM Integration Curriculum Assessment (STEM-ICA) tool developed by Guzey et al. (2016). This modified STEM-ICA tool consists of seven specific items that are closely aligned with what has been suggested in the framework for STEM integration in the classroom (Moore et al. 2014; Moore et al. 2014) as important considerations for integrated STEM lessons and curriculum. The seven items include a motivating and engaging context, participation in engineering design, the integration of science and mathematical content, the inclusion of inquiry-based instructional strategies, and a focus on teamwork and communication. Each item in the STEMICA is rated on a 5-point scale from 0 to 4 (0: not present, 1: weak, 2: adequate, 3: good, 4: excellent). Yes or No questions were completed to help reviewers to respond to different indicators within each of the items. The fourth data source was an online post-lesson survey that each participant individually completed within 1 week of their triad teaching the engineering design lesson in the classroom (Additional file 2).

\section{Data analysis}

A content analysis approach (Schreier 2012) was utilized to understand how participants integrated STEM concepts across the four phases of learning: PD experience, planning phase following the PD experience, enactment of their engineering design lesson, and post-enactment of their lesson. Within a content analysis, meaning is constructed through a systematic assignment of sections of text into categories within a coding frame that can be pre-established or emergent (Schreier 2012). Specific to a summative approach to content analysis, data analysis begins with searches for occurrences of the identified STEM content (Hsieh and Shannon 2005) and is later used to identify and contextualize interpretation for the content (Morgan 1993). To accomplish this, both researchers analyzed the data across triads. To help with the replicability of a content analysis across multiple texts and coders, it is important to specify the recording process to help ensure that the researchers identified and coded the same sections of text (Krippendorff 2013). To help with this process, the researchers started from the same pre-established frame, coded data independently, and then met to reconcile efforts and reach intercoder agreement on the data.

The pre-established coding frame utilized was aligned to Moore et al. (2015) STEM definition to be "the content and practices of disciplinary knowledge which include science and/or mathematics through the integration of the practices of engineering and engineering design of relevant technologies". Therefore, our codes consisted of the science, engineering, and mathematics content areas indicated and served as a starting point for the content analysis. Within this approach, researchers also had the flexibility to add categories and codes that emerged from the data during analysis. For example, Figure 1 below shows a participant's response from the survey given at the summer workshop.

As part of the survey, the participant provided a list of content within the Hexbug design challenge. The content coded within this response showed indication of the pre-established content codes for science (predictions, properties of materials), math (time, measurement, trial and error, angles), and engineering (designing) content. Codes also emerged from this response that did not fit with the pre-established content codes, such as group work, and those codes were included in a different category which was later identified as a skill or practice that would or could connect to the content areas within STEM. We define skill or practice based off of work within teacher education focused on high-leverage practices for teaching specifically as skills or practices that help students learn, are used across content areas, and are key components of teaching (Ball and Forzani 2009; Grossman et al. 2009).

The majority of analysis, as presented in the results, is at the level of the triad as the overarching goal of the study was to examine how the groups planned and enacted an integrated STEM lesson. However, in recognizing that the use of the triad structure is not typical for many teacher education programs or elementary classrooms, the data were collected and analyzed at the individual and triad level, when possible, to allow the ability to look across triads as well as at individual members within the triads. The surveys following the PD experience and the lesson were completed and analyzed at the individual level. While it was difficult to parse out the individual contributions of the

$$
\begin{aligned}
& \text { Time } \\
& \text { Measuremen ( }>\text { than } 12 \text { inches) } \\
& \text { Trial terror } \\
& \text { Angles (which, way would the hexbug } \\
& \text { turn?) } \\
& \text { Designing } \\
& \text { Group work } \\
& \text { Predictions of different } \\
& \text { Properties of } \\
& \text { materials (compare) } \\
& \text { Contrast) }
\end{aligned}
$$

Fig. 1 Coding example 
various members within the lesson planning and enactment data, an attempt was made through a specific post-survey question that asked each member to identify their role and contribution to the planning and implementation as well as noting the roles of each member within the field notes.

\section{Results}

The purpose of this study was to better understand the extent to which triads were able to use the context of an engineering design challenge to integrate and incorporate STEM concepts into their classroom. We report results for the occurrences of STEM concepts within each phase of learning and then discuss the interpretations of these results across all phases.

\section{STEM integration phase one: professional development survey}

The first phase of learning for participants occurred within the PD workshop. After participation in the Hexbug activity, as a learner, participants were asked to reflect on their experiences and possible content connections in a survey (Additional file 1). Our analysis of responses indicated that all 30 participants identified STEM content connections within in the Hexbug engineering design activity. We provide an overview of all content and skills or practices reported by each triad in Table 1 below.

As seen in Table 1 above, all ten of the triads were able to identify multiple STEM concepts that were or could be integrated into the Hexbug engineering design activity. When looking at mathematics concepts, all 10 triads identified connections to measurement, nine out of the 10 groups identified concepts related to geometry and half of the triads reported connections to problem solving and time. There were 13 different science concepts identified across the triads with the most common responses including properties of materials and experimentation. The high frequency of asterisks under the engineering-related concepts within Table 1 represent the fact that the triads were able to identify a large number and variety of engineering concepts that could connect to the Hexbug design activity. The engineering concepts that were reported by more than half of the groups included reference to an engineering design process, the need for criteria or constraints, planning and redesign, and the use of designing and building within the activity. While there was a possibility that this area would be higher due to the fact that each triad has an engineering graduate student, the individual level analysis revealed similar numbers of engineering concepts mentioned across the three groups suggesting all of the participants more frequently identified engineering concepts before working together as a triad. The engineering fellows identified 37 concepts and the student teachers and cooperating teacher identified just slightly less with 35 and 32, respectively.

\section{STEM integration phase two: lesson plan}

Once participants completed the PD workshop, triads began working in the elementary classroom. As part of this effort, triads were asked to submit their enhanced Hexbug lesson plan as they intended to enact in the classroom. A summative content analysis of the 10 lesson plans provided insight into the planned instruction and how each of the triads were intending to use the Hexbug activity as the basis for their integrated STEM lesson. The findings in Table 2 below provide an overview of the content and skills or practices that were identified in the lesson plans. Out of the 10 triads, four lesson plans integrated both math and science concepts within the engineering design challenge. For the remaining six groups, one integrated math and engineering, three integrated science and engineering, and two lesson plans included engineering design only.

The results of the analysis indicated that while seven of the lesson plans were very similar to the Hexbug activity that was experienced in the PD, six of those lesson plans incorporated of additional engineering components, such as adding a context, adding a more explicit planning phase where students had to get the plans approved, adding a redesign phase or changing the number and type of supplies. For example, one triad created a lesson plan with a context of a new Superhero, the Hexbug. Another triad focused on the Hexbug being a rover that would have a mission on Mars. Only one lesson plan was found to be almost identical to what was presented in the PD with the focus on meeting criteria, building, testing, and then sharing designs. Despite finding seven triads with science concepts integrated into the lesson plan and five lesson plans with math concepts, very few of the lessons explicitly identified a science or math content learning goal. Rather, nine of the lesson plans emphasized introducing the engineering design process with eight of those lessons focusing on skills or practices such as team work or collaboration.

\section{STEM integration phase three: enactment of lesson}

In the third phase, triads were asked to implement their version of the Hexbug lesson in their classroom. There were two data sources for this phase of integration, observer field notes and the modified STEM-ICA tool (Guzey et al. 2016). Our summative content analysis of the observer field notes indicated that the enactment of the Hexbug activity was implemented in all 10 classrooms, with all three members of each of the triads co-teaching the lesson. Overall, the enacted lessons included low levels of integrated science and mathematics content and a focus on engineering. Also, similar to phase two (lesson plans), seven triads implemented 
Table 1 Content and skills reported on pre-survey
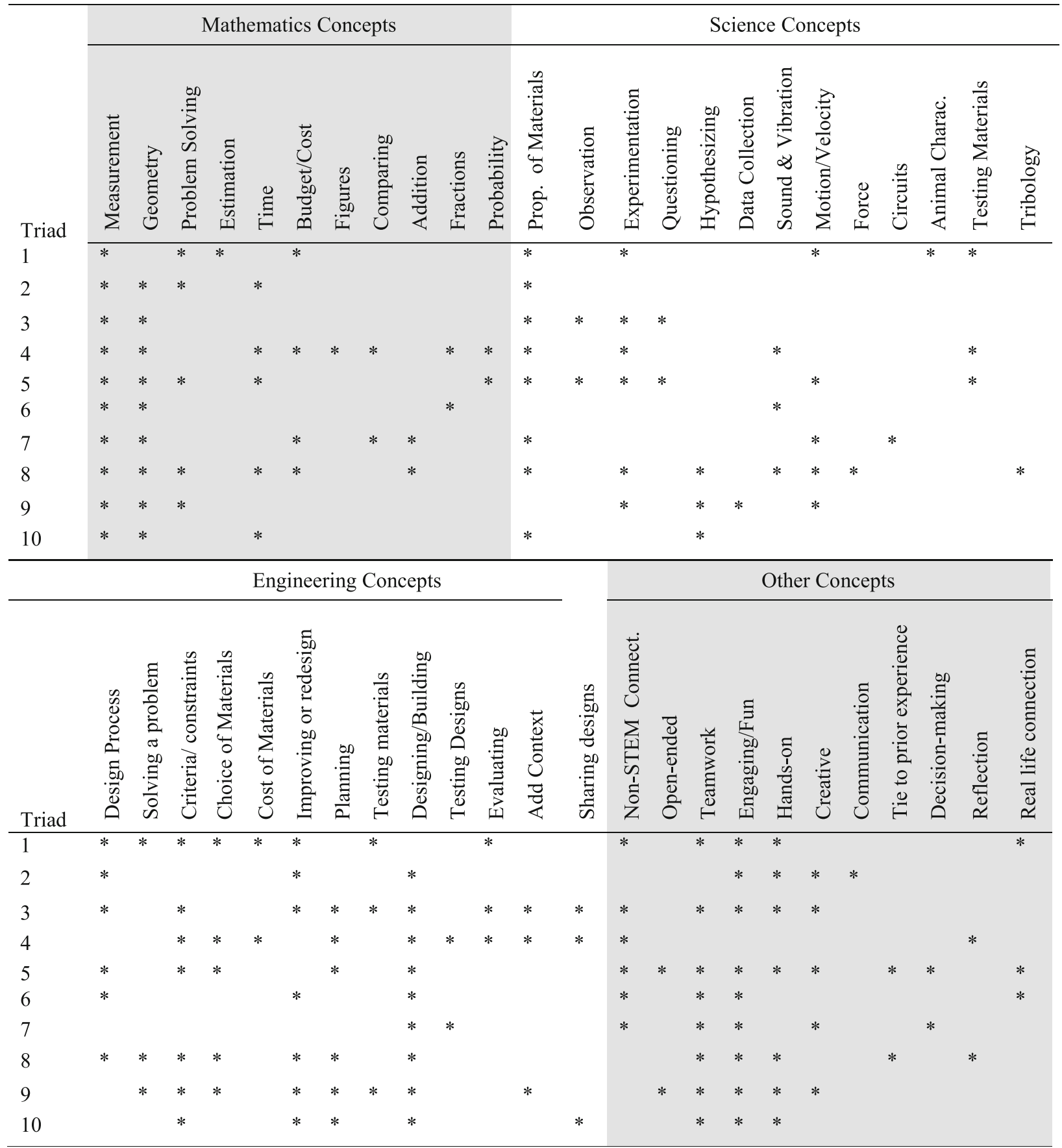

lessons that were very similar to what they experienced during the PD with two groups enacting almost identical lessons. We represent the content present in the enacted lessons in Table 3 below.

There were minimal observations of lessons that explicitly integrated across STEM concepts with only two triads both integrating math and science concepts, one triad asking students to use measurement and another integrating science only. Rather, the content learning focused mostly on engineering design and skills or practices, such as teamwork. Six of the triads worked to incorporate a context into their lesson plans, which was three more then seen in the lesson plans. While nine triads explicitly mentioned incorporating the engineering design process in their lesson plans, during enactment, only five groups explicitly mentioned the design process and only one triad executed all stages. For example, many groups had a visual of the engineering design 
Table 2 Content and skills included in lesson plans

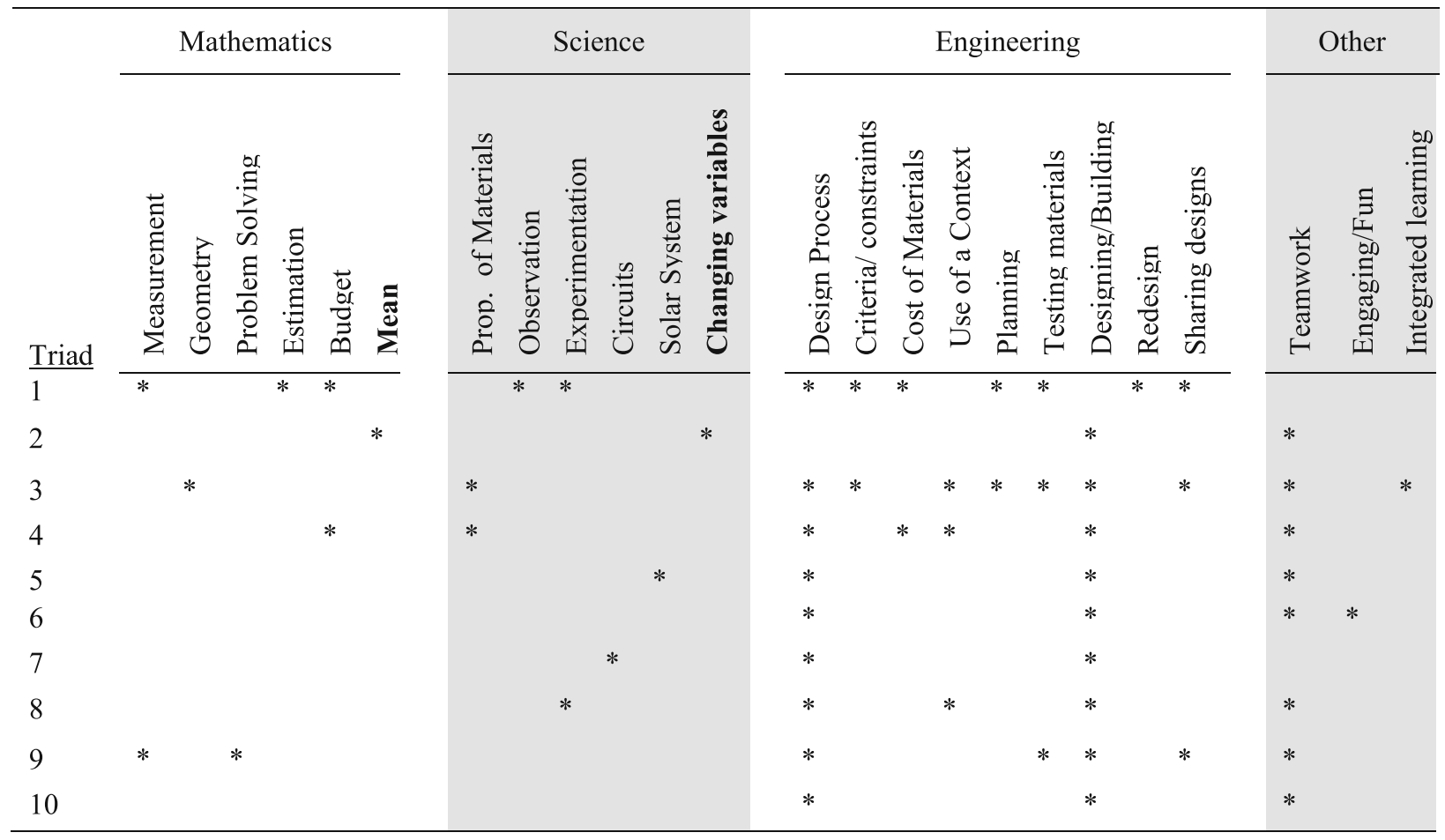

process posted in the classroom but made minimal reference to it during the lesson. Another common occurrence during enactment was that only four of the groups gave adequate planning time with the requirement to have students' plans approved before starting to build their designs.

To further analyze the enacted Hexbug lessons and the incorporation of STEM concepts, the second part of the data from the enacted lessons, scores from the modified STEM-ICA tool (Guzey et al. 2016) were analyzed. This tool identifies important considerations regarding what should be included when designing and implementing integrated STEM lessons and therefore provided a measure that could be used to compare across triads for enacted, integrated STEM concepts. Table 4 presents the average score (on a 5-point scale from 0-4) for each triad's enacted lesson for each of the seven items.

As presented in Table 4, there was an overall large focus on teamwork and the inclusion of inquiry-based strategies, with most groups scoring between good and excellent for teamwork and adequate and good for instructional strategies. The scores for STEM content were the highest in engineering design with a rating of 2 , or adequate, but much less with a rating of 1 , or poor, for the integration of math and science content. Despite the intention for the lesson to be an engineering design lesson, the ranking of adequate was largely due to the fact that several lessons either did not have students work through an entire design process or lacked the inclusions of a context, client, or constraints. The findings from the STEM-ICA were similar to the content analysis of the observer field notes which indicated limited connections to disciplinary science or mathematics content, adequate ratings related to engineering and a stronger emphasis on the representation of skills or practices (i.e., teamwork).

\section{STEM integration phase four: post-lesson survey}

The last phase of learning for participants occurred after classroom enactment of the Hexbug activity. Through the use of an online post-survey (Additional file 2), participants were asked questions to individually reflect on the Hexbug lesson. The survey allowed for an individual level of analysis to better understand each triad member's role within the lesson and across each phase of integration. Collectively, seven of the triads mentioned that they co-planned the lesson with all members involved and only one of the groups identified that the teacher took the lead on the planning and teaching of the lesson. Six of the triads mentioned that the student teacher and engineering fellow took the lead with most of them mentioning that the engineering fellow introduced engineering and the design process and then the student teacher introduced the context and led the rest of the lesson. There were two triads where the teacher 


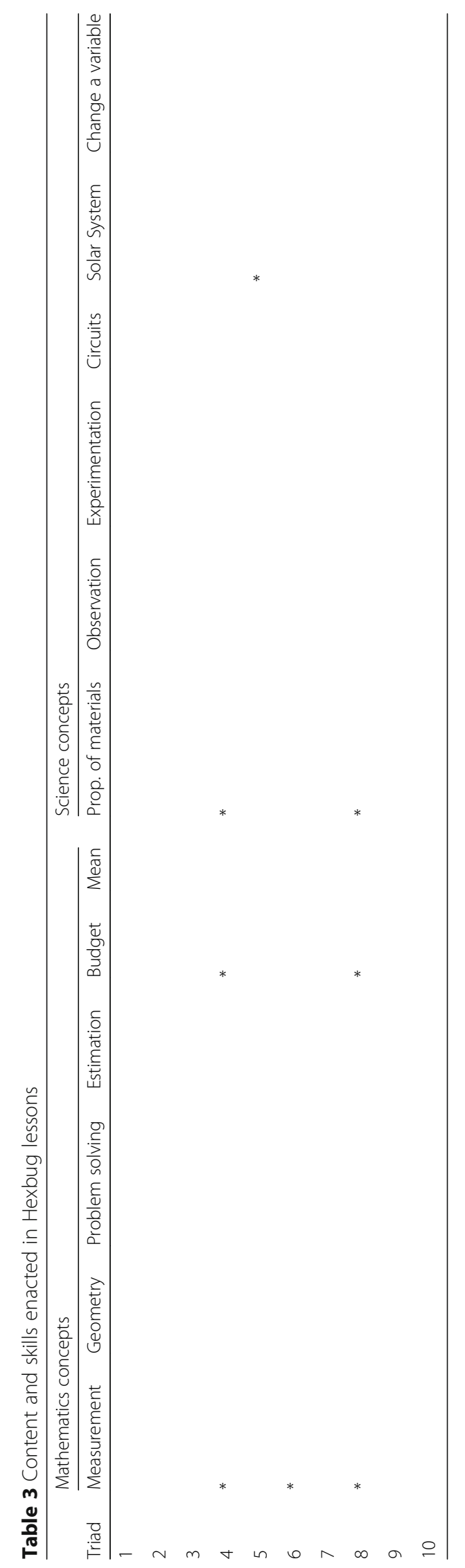




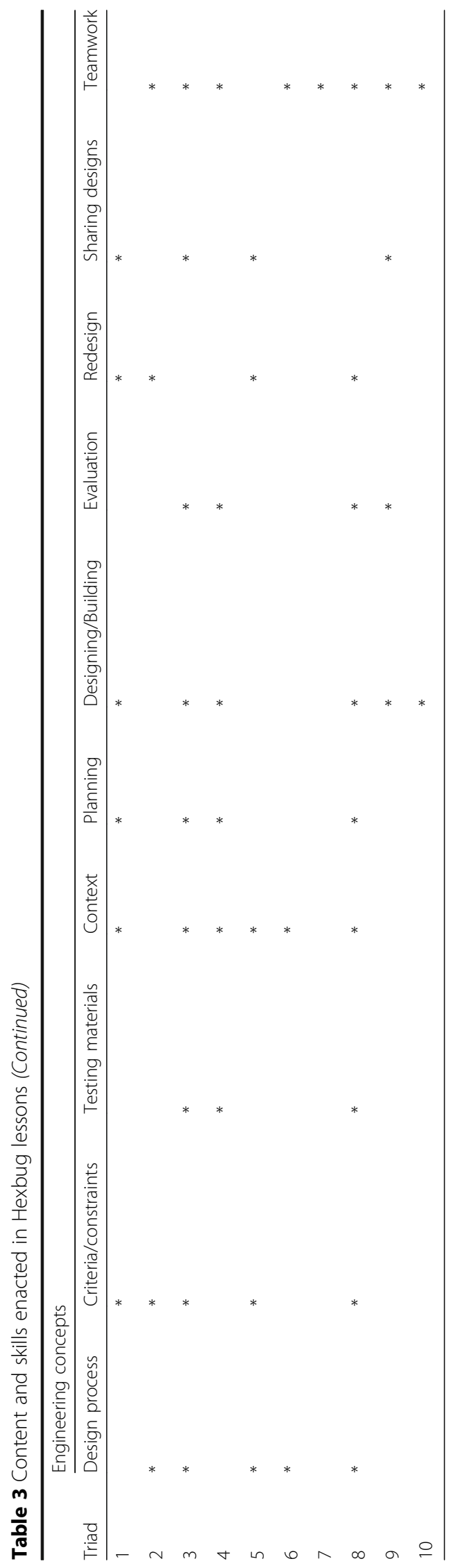


Table 4 Average score for enacted lesson content by triad

\begin{tabular}{|c|c|c|c|c|c|c|c|}
\hline \multirow[b]{2}{*}{ Triad } & \multirow{2}{*}{$\begin{array}{l}\text { Math } \\
\text { Content }\end{array}$} & \multirow{2}{*}{$\begin{array}{l}\text { Science } \\
\text { Content }\end{array}$} & \multicolumn{2}{|l|}{ Engineering } & \multicolumn{3}{|l|}{ Skills or practices } \\
\hline & & & Motivating context & Engineering design & Instruction strategies & Focus on teamwork & Focus on communication \\
\hline 1 & 0 & 0 & 4 & 2.5 & 1.5 & 2.5 & 0.5 \\
\hline 2 & 0 & 0 & 1 & 1 & 2 & 2 & 1 \\
\hline 3 & 0.5 & 0.5 & 3 & 2.5 & 3 & 3.5 & 2.5 \\
\hline 4 & 0 & 0 & 3 & 3 & 2 & 3 & 3 \\
\hline 5 & 0 & 0.5 & 4 & 3 & 3.5 & 4 & 2 \\
\hline 6 & 0.5 & 0.5 & 1.5 & 2 & 2.5 & 3.5 & 2.5 \\
\hline 7 & 0 & 0 & 0 & 0 & 1 & 3 & 0 \\
\hline 8 & 2 & 0 & 3 & 4 & 3 & 3 & 2 \\
\hline 9 & 0 & 0.5 & 0 & 0 & 2 & 3 & 0.5 \\
\hline 10 & 0 & 0 & 0 & 2 & 1 & 3 & 0 \\
\hline Average & 0.3 & 0.2 & 1.95 & 2 & 2.15 & 3.05 & 1.4 \\
\hline
\end{tabular}

took the overall lead for the lesson with the engineering fellows introducing and explaining the engineering component. While the engineering fellows were most commonly responsible for introducing engineering and an engineering design process it was not exclusive to the fellows, as many triads reported that all members were involved in the planning and delivery of engineering content.

Beyond the roles each triad member had, our analysis of the survey responses indicated that triads experienced success in the Hexbug lesson, mainly identifying skills or practices as the goal of the lesson. Further, barriers were provided for why a lesson might not have been enacted as intended. For example, one teacher stated "It (Hexbug challenge) might have been easier and more meaningful if students had a better understanding of the entire process (engineering design process) before they started. Perhaps we could do a simpler project for the first time." Other participants noted that students needed more direction for the engineering design challenge alluding to classroom management being an issue or the limitation of time. Still, all of the participants identified STEM content included within their Hexbug design challenge as enacted. From participant reflection on how the lesson was enacted and the STEM concepts that were included, nine triads identified both science and math concepts with an overarching focus on teamwork and using an engineering design process. We illustrate this in Table 5 below.

Similar to what was seen in the other phases (lesson plan and enactment) and not surprising when considering the foundation for this lesson was an engineering design challenge, the area with the most detailed answers in terms of reflection and identifying what occurred during the lesson was within engineering. All 10 of the triads noted that they had students designing and building a maze and nine of the groups explicitly mentioned that they covered an engineering design process. There was a range in terms of the extent to which groups identified specific steps within engineering design with three groups identifying the need to evaluate their designs and only one of the groups mentioning the importance of having students redesign. There was also less of a focus in reflections on criteria and constrains than seen in lesson plans and enacted lessons. Interestingly, five of the groups reported a lesson focus of explaining and representing engineering and what engineers do which had not been explicitly identified prior to this phase.

When looking across the 10 triads at the science and math concepts that were identified by multiple triads, there was some overlap with at least three of the triads identifying measurement, addition, and properties of materials. There were also several unique concepts that were reported including problems solving, mean, and decimal addition specific to math and observation, prediction, circuits, solar system, variables, and sound in science. This suggests that while the triads all used the same engineering design challenge as the basis for their lessons, the triads were able to identify multiple science and math concepts that could be integrated along with the engineering design challenge. When compared to the results in Table 4, these findings of identifying multiple science and math concepts within their lessons are in contrast to the researchers' analysis of what was enacted, with the exception of engineering content.

\section{Discussion}

When looking across the analysis of the various data sources several findings emerged that can provide insight into the ways in which teachers are integrating engineering-design-based STEM into their elementary classrooms and the needed supports to further STEM integration in the classroom. We discuss these and implications for future research below. 
Table 5 Content and skills reported in post lesson survey

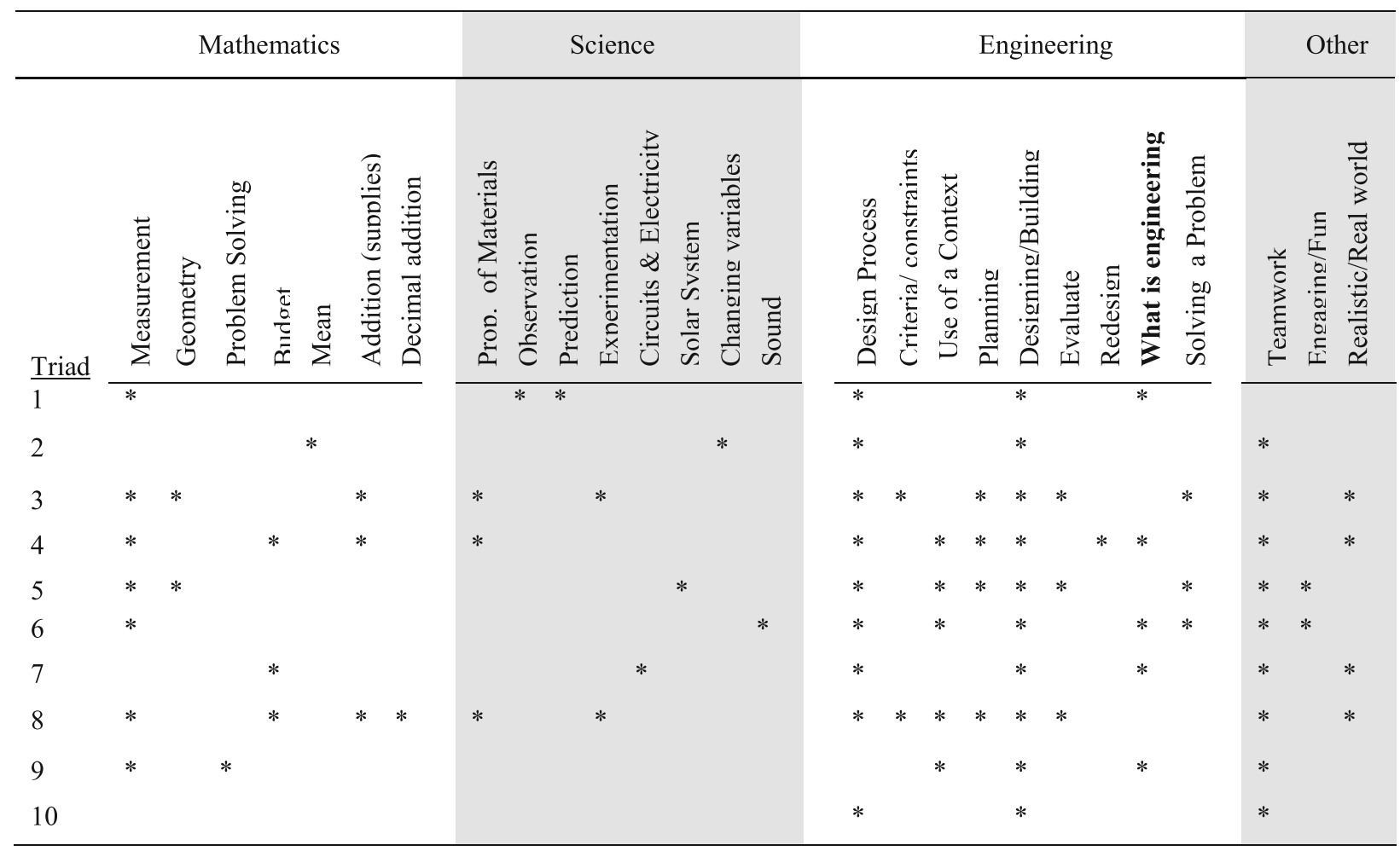

Engineering design as a context for integration within our study was successful in terms of helping participants identify STEM content connections that could be implemented within an engineering design activity. This is similar to what has been suggested by other research that engineering design can be used to facilitate integrated STEM (Brophy et al. 2008; Fortus et al. 2004; Kolodner et al. 2003; Bethke Wendell and Rogers 2013). In addition to being able to use engineering design to facilitate integration, all members of the triads were able to identify multiple STEM content connections that could be used with the Hexbug lesson. Additionally, half of the triads identified the need for the engineering design challenge to be situated within an engaging context for their students. As aligned with the literature, participants saw the importance of a context to provide an opportunity for students to engage with real-world contexts and problems that are authentic to engineering and illustrate connections to the real world (Bers et al. 2002; Brophy et al. 2008; Cunningham and Lachapelle 2014; Moore et al. 2014; Stohlmann et al. 2012). In addition to a focus on the context, four triads modified the Hexbug activity to include an explicit focus on intentional planning and created either individual or group plans prior to building and testing their designs. These trends in the data indicated that several groups were able to incorporate more accurate views of engineering design as a systematic and thoughtful process (Dym et al. 2005) into their classroom instruction. Further research is needed to understand the possible reasons for the enhancement of the engineering component, when there is limited evidence of math or science enhancement.

Within our study there was a decreased focus on STEM concepts as participants moved towards enactment. The only category where the researchers observed a pattern of consistency across the concepts within the four different phases of learning was for engineering. This suggests that within PD experiences, more emphasis is needed on how to connect content within lessons. Participants were able to conceptualize the content, but needed more support to enact these connections in the classroom. Within the PD provided to participants, this knowledge preceded the Hexbug design challenge. Further inquiry is needed to determine if classroom integration of STEM concepts would be further enhanced if efforts within PD experiences worked to bridge learning opportunities from planning to enacting in more purposeful and scaffolded ways.

Within the data that was collected it was difficult to know why, despite asking triads to enhance the lesson to include more content, there was a shift away from integrating science and mathematics content into the design challenge. We report four possible conjectures for this finding. First, participants reported barriers (time, perceived difficulty) that were reflected in the enacted lesson and post-lesson survey. Triads reported having to 
make changes or alter the lesson plan due to the amount of time needed for the activity. Further, although groups worked to brainstorm concepts to enhance the activity to make it more representative of engineering designbased STEM and included some of these concepts in their lesson plan, the content specific to the STEM areas were limited and very siloed. Therefore, teachers needed more support in the planning and enactment of the lesson to ensure that the intended content is enacted in an integrated way. This becomes critical in the k-5 classrooms as, O'Brien et al. (2014) express, there is a limited number of k-5 teachers with a STEM specialization and "a lack of STEM subject matter expertise and experiences, coupled with high anxiety and low self-efficacy can lead to low teacher effectiveness and lack of interest in STEM subjects by k-5 students" (p. 280).

A second possibility for the decrease in math and science content was the difference in perceived integration of STEM content as found by the post-survey compared to what was reported in and what the researchers' identified when observing the enacted lessons. The teachers were being asked to approach STEM in an integrated way, which was primarily new to them. When ask what content was covered, many reported more science and math content then the researchers observed. Therefore, perception of enactment was slightly different from what was observed. Additional research is needed to analyze under what circumstances we see the most discrepancy and then learn the best ways to support teachers as they implement integrated STEM curricula. This finding is supported by other research that expresses the importance of studying the intended and enacted curricula as they embody "institutionalized beliefs about what materials is important" (Prevost et al. 2014, p. 217). Therefore, as teachers make decisions about integrating STEM concepts, further analysis into these decisions is needed to understand connections among content knowledge, beliefs, and student learning around integrated STEM.

Third, integration of STEM content is difficult (National Research Council 2014; Prevost et al. 2014), and to be able to explicitly integrate STEM, teachers need to have a good understanding of the content that is being integrated. This can present a challenge for elementary teachers, who often have limited disciplinary knowledge within science, technology, engineering, and mathematics (Sanders 2008; Ejiwale 2013). However, Kelley and Knowles (2016) suggest that the key to preparing STEM educators is to first begin by grounding their conceptual understanding of integrated STEM education within key learning theories, and pedagogical approaches, and then building awareness of research results of current STEM educational initiatives. In addition to building pedagogical and content knowledge within STEM, Roehrig et al. (2012) suggest that helping teachers develop beliefs and knowledge related to the importance of integrated STEM as well as building an understanding of what integrated STEM instruction looks like in the classroom can help ensure more successful implementation. Our findings support this need to more explicitly help teachers to connect ideas across disciplines as well as developing a method for un-siloing STEM content and working towards a more integrated approach. These findings help inform decisions for PD developers and facilitators as we acknowledge the trajectory of learning needed for integrated STEM instruction and the scaffolded experiences and supports teachers need to develop pedagogy and content in STEM.

Last, participants within our study saw engineering content as a skill or practice versus academic content. Many reported that the Hexbug activity was fun and engaging. The triads allowed students to tinker with the activity versus engaging students to learn engineering content and bridge science and math. In several of the lessons, there was a large focus on using engineering to help develop teamwork and other skills that engineers demonstrate in the work place. This view of engineering content as a skill or practice versus a context for integrating an academic content likely contributed to the decrease in science and mathematics content. This finding is similar to Carson and Campbell (2007) who reported that teachers increased their use of problem-solving strategies, however, not related to engineering within their study. Future research is needed to understand how to support teachers to engage in this change in practice as they work to position engineering as content within a classroom.

In summary, our findings suggest the importance for PD experiences to go beyond teacher content knowledge and support teachers in strategies for enactment of an integrated approach. Possible research could investigate how rehearsals for enactment support teacher ability to more robustly integrate STEM within the classroom. Further, within PD experiences, these connections should be modeled and discussed. Given an opportunity to engage in the activity first as a learner, and then work to implement in the classroom might provide a stronger foundation for enactment. Within our study, we hoped that the expertise of each triad member could provide this support, but still many of the observed lessons modeled that to which to triads experienced within the PD experience with minimal integration of STEM concepts. This highlights the known impact PD has on learning and the importance for relevant and purposeful learning experiences.

\section{Conclusions}

Overall, results of our study suggest that while all of the triads were able to initially identify multiple ways in which engineering design could be used as a context for the integration of other disciplines, when it came time for 
enactment the connections between multiple disciplines were largely missing. This highlights the challenge for participants to sustain the integration of STEM concepts across each phase of conceptualization. As we work to better understand how to integrate STEM into the elementary classroom, we must remember to support teacher learning not only for the content of the STEM disciplines but also for the needed pedagogy of enactment.

\section{Additional files}

Additional file 1: Hexbug Lesson Survey. (DOCX $29 \mathrm{~kb}$ )

Additional file 2: Post Lesson Survey. (DOCX $30 \mathrm{~kb}$ )

\section{Acknowledgements}

The authors would like to thank Joanne Olson, Chris Spinler and Jacob Pleasants for their involvement in collecting data reported in this paper as part of the Trinect Project.

\section{Funding}

This work was supported by the National Science Foundation under grant \# 1440446. Any opinions, findings, conclusions, or recommendations expressed in this material are those of the authors and do not necessarily reflect the views of the National Science Foundation.

\section{Authors' contributions}

The authors collaborated on the design and execution of the study, including data collection and analysis. Both authors read, edited, and approved this manuscript.

\section{Competing interests}

The authors declare that they have no competing interests.

\section{Author details}

${ }^{1}$ Iowa State University, 1660E Lagomarcino Hall, Ames, IA 50011, USA. ${ }^{2}$ lowa

State University, 0624C Lagomarcino Hall, Ames, IA 50011, USA.

Received: 31 August 2016 Accepted: 12 February 2017

Published online: 27 March 2017

\section{References}

Adams, R., Evangelou, D., English, L., Figueiredo, A. D., Mousoulides, N., Pawley, A. L., \& Wilson, D. M. (2011). Multiple perspectives on engaging future engineers. Journal of Engineering Education, 100(1), 48-88.

Ball, D. L., \& Forzani, F. M. (2009). The work of teaching and the challenge for teacher education. Journal of Teacher Education, 60(5), 497-511.

Berland, L. K. (2014). Designing for STEM integration. Journal of Pre-College Engineering Education Research, 3(1), Article 3. http://dx.doi.org/10.7771/2157-9288.1078.

Bers, M. U., Ponte, I., Juelich, K., \& Schenker, J. (2002). Teachers as Designers Integrating Robotics in Early Childhood Education. Information Technology in Childhood Education Annual, 2002, 123-145. Retrieved from http://www. editlib.org/p/8850/

Bethke Wendell, K., \& Rogers, C. (2013). Engineering Design-Based Science, Science Content Performance, and Science Attitudes in Elementary School. Journal of Engineering Education, 102(4), 513-540.

Borko, H., Jacobs, J., Eiteljorg, E., \& Pittman, M. E. (2008). Video as a tool for fostering productive discussions in mathematics professional development. Teaching and Teacher Education, 24, 417-436.

Breiner, J. M., Harkness, S. S., Johnson, C. C., \& Koehler, C. M. (2012). What is STEM? A discussion about conceptions of STEM in education and partnerships. School Science and Mathematics, 112(1), 3-11. doi:10.1111/j.1949-8594.2011.00109.x.

Brophy, S., Klein, S., Portsmore, M., \& Rodgers, C. (2008). Advancing Engineering Education in P-12 Classrooms. Journal of Engineering Education, 97(3), 369-387. doi:10.1002/j.2168-9830.2008.tb00985.x.

Bybee, R. W. (2010). K-12 engineering education standards: Opportunities and barriers. In National Research Council (Ed.), Standards for K-12 engineering education? (pp. 55-66). Washington: The National Academies Press.
Bybee, R. (2013). The case of STEM education: Challenges and opportunities. Arlington: NSTA Press.

Capobianco, B. M., \& Rupp, M. (2014). STEM Teachers' Planned and Enacted Attempts at Implementing Engineering Design-Based Instruction. School Science and Mathematics, 114(6), 258-270.

Carlson, L., \& Sullivan, J. (2004). Exploiting design to inspire interest in engineering across the K-16 engineering curriculum. International Journal of Engineering Education, 20(30), 372-380.

Carson, R., \& Campbell, P. B. (2007). Museum of Science: Engineering is Elementary; Exploring the impact of EiE on participating teachers. Groton: Campbell-Kibler Associates, Inc.

Crismond, D. (2001). Learning and using science ideas when doing investigate and redesign tasks: A student of naive, novice and expert designers doing constrained and scaffolded design work. Journal of Research in Science Teaching, 38(7), 791-820.

Cunningham, C. (2008). Elementary Teacher Professional Development In Engineering: Lessons Learned From Engineering Is Elementary. (Paper presented at 2008 Annual Conference \& Exposition, Pittsburgh, Pennsylvania). Retrieved from https://peer.asee.org/4414.

Cunningham, C. M., \& Hester, K. (2007). Engineering is elementary: an engineering and technology curriculum for children. Honolulu: Proceedings of the American Society for Engineering Education Annual Conference and Exposition.

Cunningham, C. M., \& Lachapelle, C. P. (2014). Designing engineering experiences to engage all students. In S. Purzer, J. Strobel, \& M. Cardella (Eds.), Engineering in pre-college settings: synthesizing research, policy, and practices (pp. 117-142). Lafayette: Purdue University Press.

Diefes-Dux, H. A. (2014). In-service teacher professional development in engineering education: early years. In S. Purzer, J. Strobel, \& M. Cardella (Eds.), Engineering in precollege settings: Synthesizing Research, Policy, and Practices. Lafayette: Purdue University Press.

Dym, C. L., Agogine, A. M., Eris, O., Frey, D. D., \& Leifer, L. J. (2005). Engineering Design Thinking, Teaching, and Learning. Journal of Engineering Education, 94(1), 103-120

Ejiwale, J. (2013). Barriers to successful implementation of STEM education. Journal of Education and Learning, 7(2), 63-74.

English, L. D. (2015). STEM: Challenges and Opportunities for Mathematics Education. In K. Beswick, T. Muir, \& J. Wells (Eds.), Proceedings of the 39th Conference of the International Group for the Psychology of Mathematics Education (Vol. 1, pp. 4-18). Hobart: PME.

English, L. D., \& King, D. T. (2015). STEM learning through engineering design: fourth-grade students' investigations in aerospace. International Journal of STEM Education, 2(14), 1-18. doi:10.1186/s40594-015-0027-7.

Estapa, A., Pinnow, R. J., \& Chval, K. B. (2016). Video as a professional development tool to support novice teachers as they learn to teach English language learners. The New Educator, 12(1), 85-104.

Fortus, D., Dershimer, R. C., Krajcik, J., Marx, R. W., \& Mamlok-Naaman, R. (2004). Design-based science and student learning. Journal of Research in Science Teaching, 41(10), 1081-1110.

Gamoran, A., Secada, W., \& Marrett, C. (2006). The organizational context of teaching and learning (Handbook of the sociology of education, pp. 37-63).

Garet, M. S., Porter, A. C., Desimone, L., Birman, B. F., \& Yoon, K. S. (2001). What makes professional development effective? Results from a national sample of teachers. American Educational Research Journal, 38, 915.

Grossman, P., Compton, C., Igra, D., Ronfeldt, M., Shahan, E., \& Williamson, P. (2009). Teaching practice: A cross-professional perspective. Teachers College Record, 111(9), 2055-2100.

Guskey, T. R. (1986). Staff development and the process of teacher change. Educational Researcher, 15(5), 5.

Guskey, T. R. (2002). Does It Make a Difference? Evaluating Professional Development. Educational Leadership, 59, 45-51.

Guzey, S. S., Tank, K. M., Wang, H.-H., Roehrig, G., \& Moore, T. J. (2014). A high-quality professional development for teachers of grades 3-6 for implementing engineering into classrooms. School Science and Mathematics, 114(3), 139-149. doi:10.1111/ssm.12061.

Guzey, S. S., Moore, T. J., \& Harwell, M. (2016). Building Up STEM: An Analysis of Teacher-Developed Engineering Design-Based STEM Integration Curricular Materials. Journal of Pre-College Engineering Education Research, 6(1), 2.

Hsieh, H. F., \& Shannon, S. E. (2005). Three approaches to qualitative content analysis. Qualitative Health Research, 15(9), 1277-1288.

Johnson, C. C. (2013). Conceptualizing integrated STEM education. School Science and Mathematics, 113(8), 367-368. doi:10.1111/ssm.12043. 
Kelley, T. R., \& Knowles, J. G. (2016). A conceptual framework for integrated STEM education. International Journal of STEM Education, 3(1), 1-11.

Kolodner, J. L., Camp, P. J., Crismond, D., Fasse, B. B., Gray, J. T., Holbrook, J., Ryan, M., \& Puntambekar, S. (2003). Problem-based learning meets case- based reasoning in the middle-school science classroom: Putting a learning-bydesign curriculum into practice. Journal of the Learning Sciences, 12(4), 495-548. doi:10.1207/S15327809JLS1204_2.

Krippendorff, K. (2013). Content analysis: An introduction to its methodology. Los Angeles: SAGE. Moore et. al., 2014.

Lachapelle, C. P., \& Cunningham, C. M. (2014). Engineering in elementary schools (Engineering in pre-college settings: Synthesizing research, policy, and practices). Lafayette: Purdue Univ.

Mehalik, M. M., Doppelt, Y., \& Schunn, C. D. (2008). Middle-school science through design-based learning versus scripted inquiry: Better overall science concept learning and equity gap reduction. Journal of Engineering Education, 97(1), 71-85. doi:10.1002/j.2168-9830.2008.tb00955.x.

Moore, T. J., Guzey, S. S., \& Brown, A. (2014). Greenhouse design to increase habitable land: An engineering unit. Science Scope, 37(7), 51-57.

Moore, T. J., Stohlmann, M. S., Wang, H.-H., Tank, K. M., Glancy, A. W., \& Roehrig, G. H. (2014). Implementation and integration of engineering in K-12 STEM education. In S. Purzer, J. Strobel, \& M. Cardella (Eds.), Engineering in precollege settings: Synthesizing Research, Policy, and Practices. Lafayette: Purdue University Press.

Moore, T. J., Johnson, C. C., Peters-Burton, E. E., \& Guzey, S. S. (2015). The need for a STEM road map. In C. C. Johnson, E. E. Peters-Burton, \& T. J. Moore (Eds.), STEM Road Map: A Framework for Integrated STEM Education. New York: Routledge.

Morgan, D. L. (1993). Qualitative content analysis: A guide to paths not taken. Qualitative Health Research, 3, 112-121.

National Academy of Engineering \& National Research Council. (2009). Engineering in K-12 Education: Understanding the status and improving the prospects. Washington: The National Academies Press.

National Research Council. (2011). Successful K-12 STEM Education: Identifying effective approaches in science, technology, engineering, and mathematics. Washington: The National Academies Press.

National Research Council. (2012). A framework for K-12 science education: Practices, crosscutting concepts, and core ideas. Washington: The National Academies Press.

National Research Council. (2014). STEM integration in K-12 education: Status, prospects, and an agenda for research. Washington: National Academies Press.

NGSS Lead States. (2013). Next generation science standards: For states, by states. Washington: The National Academies Press.

O'Brien, S., Karsnitz, J., Sandt, S., Bottomley, L., \& Parry, E. (2014). Engineering in preservice teacher education. In S. Purzer, J. Strobel, \& M. Cardella (Eds.), Engineering in Pre-college Settings: Synthesizing Research, Policy, and Practices (pp. 277-300).

Prevost, A., Nathan, M., \& Phelps, L. A. (2014). High School Pre-Engineering Curricula: Assessing Teacher Beliefs, Intended Curriculum, and Enacted Curriculum. In S. Purzer, J. Strobel, \& M. Cardella (Eds.), Engineering in precollege settings: Synthesizing Research, Policy, and Practices. Lafayette: Purdue University Press.

Purzer, S., Hathaway Goldstein, M., Adams, R., Xie, C., \& Nourian, S. (2015). An exploratory study of informed engineering design behaviors associated with scientific explanations. International Journal of STEM Education, 2, 9. doi:10. 1186/s40594-015-0019-7.

Roehrig, G. H., Moore, T. J., Wang, H. H., \& Park, M. S. (2012). Is Adding the E Enough? Investigating the Impact of K-12 Engineering Standards on the Implementation of STEM Integration. School Science and Mathematics, 112(1), 31-44. doi:10.1111/j.1949-8594.2011.00112.x.

Sanders, M. E. (2008). STEM, STEMeducation, STEMmania. The Technology Teacher, $1,20-26$.

Schreier, M. (2012). Qualitative content analysis in practice. Thousand Oaks: Sage.

Sheppard, S. D., Macatangay, K., Colby, A., \& Sullivan, W. M. (2009). Educating Engineers: Designing for the Future Field Book Highlights and Summary.

Stohlmann, M., Moore, T. J., \& Roehrig, G. H. (2012). Considerations for Teaching Integrated STEM Education. Journal of Pre-College Engineering Education Research, 2(1), 28-34. doi:10.5703/1288284314653.

Wang, H.-H., Moore, T. J., Roehrig, G. H., \& Park, M. S. (2011). STEM integration: Teacher perceptions and practice. Journal of Pre-College Engineering Education Research, 1(2), 1-13. doi:10.5703/1288284314636.

\section{Submit your manuscript to a SpringerOpen ${ }^{\circ}$ journal and benefit from:}

- Convenient online submission

- Rigorous peer review

- Immediate publication on acceptance

- Open access: articles freely available online

- High visibility within the field

- Retaining the copyright to your article

Submit your next manuscript at $\gg$ springeropen.com 